OPEN ACCESS

Edited by:

Luc Pellerin,

University of Poitiers,

France

Reviewed by:

Lezi E,

Medical College of Wisconsin,

United States

Bengt Kayser,

University of Lausanne,

Switzerland

*Correspondence:

Toshio Mikami

mikami@nms.ac.jp

Specialty section:

This article was submitted to

Exercise Physiology,

a section of the journa

Frontiers in Physiology

Received: 06 July 2021

Accepted: 17 August 2021

Published: 16 September 2021

Citation:

Park J, Kim J and Mikami T (2021)

Exercise-Induced Lactate Release

Mediates Mitochondrial Biogenesis in

the Hippocampus of Mice via

Monocarboxylate Transporters.

Front. Physiol. 12:736905.

doi: 10.3389/fphys.2021.736905

\section{Exercise-Induced Lactate Release Mediates Mitochondrial Biogenesis in the Hippocampus of Mice via Monocarboxylate Transporters}

\author{
Jonghyuk Park ${ }^{1}$, Jimmy Kim ${ }^{1}$ and Toshio Mikami ${ }^{2 *}$ \\ 'Department of Anatomy and Neurobiology, Graduate School of Medicine, Nippon Medical School, Tokyo, Japan, \\ ${ }^{2}$ Department of Health and Sports Science, Nippon Medical School, Tokyo, Japan
}

Regular exercise training induces mitochondrial biogenesis in the brain via activation of peroxisome proliferator-activated receptor gamma-coactivator $1 \alpha$ (PGC-1 $\alpha$ ). However, it remains unclear whether a single bout of exercise would increase mitochondrial biogenesis in the brain. Therefore, we first investigated whether mitochondrial biogenesis in the hippocampus is affected by a single bout of exercise in mice. A single bout of high-intensity exercise, but not low- or moderate-intensity, increased hippocampal PGC-1 $\alpha$ mRNA and mitochondrial DNA (mtDNA) copy number at 12 and 48h. These results depended on exercise intensity, and blood lactate levels observed immediately after exercise. As lactate induces mitochondrial biogenesis in the brain, we examined the effects of acute lactate administration on blood and hippocampal extracellular lactate concentration by in vivo microdialysis. Intraperitoneal (I.P.) lactate injection increased hippocampal extracellular lactate concentration to the same as blood lactate level, promoting PGC-1 $\alpha$ mRNA expression in the hippocampus. However, this was suppressed by administering UK5099, a lactate transporter inhibitor, before lactate injection. I.P. UK5099 administration did not affect running performance and blood lactate concentration immediately after exercise but attenuated exercise-induced hippocampal PGC- $1 \alpha$ mRNA and mtDNA copy number. In addition, hippocampal monocarboxylate transporters (MCT)1, MCT2, and brain-derived neurotrophic factor (BDNF) mRNA expression, except MCT4, also increased after highintensity exercise, which was abolished by UK5099 administration. Further, injection of 1,4-dideoxy-1,4-imino-D-arabinitol (glycogen phosphorylase inhibitor) into the hippocampus before high-intensity exercise suppressed glycogen consumption during exercise, but hippocampal lactate, PGC-1 $\alpha$, MCT1, and MCT2 mRNA concentrations were not altered after exercise. These results indicate that the increased blood lactate released from skeletal muscle may induce hippocampal mitochondrial biogenesis and BDNF expression by inducing MCT expression in mice, especially during short-term highintensity exercise. Thus, a single bout of exercise above the lactate threshold could provide an effective strategy for increasing mitochondrial biogenesis in the hippocampus.

Keywords: exercise, hippocampus, peroxisome proliferator-activated receptor gamma-coactivator $1 \alpha$, mitochondrial biogenesis, lactate, microdialysis 


\section{INTRODUCTION}

Mitochondrial dysfunction causes neurodegenerative diseases, such as Alzheimer's disease, and Parkinson's disease and metabolic diseases, such as type 2 diabetes; it is caused by physiological deterioration owing to aging and lack of exercise (Short et al., 2005; Sutherland et al., 2009; Safdar et al., 2011; Zhang et al., 2012; Rodriguez-Martinez et al., 2013). Mitochondrial biogenesis, the formation of new mitochondria in cells, is vital for mitochondrial function in various tissues. Endurance exercise training induces brain and skeletal muscle mitochondrial biogenesis (Steiner et al., 2011; Halling et al., 2019).

Peroxisome proliferator-activated receptor gamma-coactivator $1-\alpha$ (PGC-1 $\alpha$ ) is the master regulator of mitochondrial biogenesis in various cell types (Sutherland et al., 2009; Wareski et al., 2009; Lezi et al., 2013). Eight weeks of treadmill exercise training induces an increase in PGC- $1 \alpha$ mRNA expression in skeletal muscle and brain regions, including the cortex and hippocampus, with a concomitant increase in mitochondrial DNA (mtDNA) copy number, enhancing exercise performance (Steiner et al., 2011). Training adaptation reflects the accumulation of the beneficial physiological functions produced from single bouts of exercise; thus, to produce a better exercise training strategy, it is essential to understand the beneficial effects of a single bout of exercise and elucidate the mechanism underlying exercise. However, it remains unclear whether a single bout of exercise would increase mitochondrial biogenesis in the brain.

Research indicates that a single bout of exercise (low, moderate, and high intensity) increases the transcriptional regulators of mitochondrial biogenesis [PGC- $1 \alpha$, mitochondrial transcription factor A (TFAM), and nuclear respiratory factor 1 (NRF1) mRNA expression] in mice and human skeletal muscle (Safdar et al., 2009; Little et al., 2010; Tadaishi et al., 2011; Saleem and Hood, 2013; Gidlund et al., 2015), proportional to the exercise intensity used (Ikeda et al., 2008). These results suggest that even a single bout of exercise enhances mitochondrial biogenesis in skeletal muscle, and the extent of its enhancement depends on the intensity of exercise performed. On the other hand, it is unclear whether hippocampal mitochondrial biogenesis is also affected by a single bout of exercise and whether its effect, if any, depends on exercise intensity.

Skeletal muscles release lactate into the blood during exercise; blood lactate concentrations range from $\sim 3 \mathrm{mM}$ at rest to $\sim 10 \mathrm{mM}$ in mice following high-intensity exercises, which is above the lactate threshold (LT; Hu et al., 2021). LT is the time point when blood lactate concentrations start to rise from the resting level if the subjects continue to exercise with increasing exercise intensity. This time point is thought to express the increased usage of both muscle glycogen and fast muscle fibers (Billat et al., 2005). Lactate was thought to be only a waste product derived from glycolysis metabolism. However, recent studies revealed that circulating blood lactate serves as energy substrates for the skeletal muscle (Takahashi et al., 2020) and enhances skeletal muscle mitochondrial biogenesis (Rowe et al., 2013; Kitaoka et al., 2016). Additionally, lactate crosses the blood-brain barrier (BBB) through monocarboxylate transporters (MCT) in brain cells (Riske et al., 2017; El Hayek et al., 2019) and supplies the energy substrates to neurons (Kobayashi et al., 2019; Lev-Vachnish et al., 2019). For example, 6-week high-intensity interval training (HIT) increased hippocampal lactate concentration and enhanced mitochondrial biogenesis (Hu et al., 2021). In addition, HIIT also increased hippocampal brain-derived neurotrophic factor (BDNF) expression and protein, which is a necessary regulator for enhancing mitochondrial quality control, and maintaining neuronal function and survival (Freitas et al., 2018; Hu et al., 2021; Okamoto et al., 2021).

Exogenous intraperitoneally (i.p.) or orally administered lactate works the same way as endogenous lactate released from skeletal muscle during exercise. Lactate administrated chronically to mice functioned as a signal molecule that promoted adult hippocampal neurogenesis (Lev-Vachnish et al., 2019). Acute and chronic peripheral lactate administration increased extracellular lactate concentrations in hippocampal tissue, which produced antidepressant-like effects in mice (Carrard et al., 2018). Lactate administered to hippocampal cells in vitro enhanced ATP levels, PGC-1 $\alpha$, BDNF protein level, mtDNA copy number, and potentiated mitochondrial function ( $\mathrm{Hu}$ et al., 2021). We hypothesized that blood lactate increased by high-intensity exercise could promote PGC- $1 \alpha$ mRNA expression in the hippocampus and trigger hippocampal mitochondrial biogenesis.

Lactate derived from brain glycogen is critical for neurons. In brief, lactate generated by glycogen degradation in astrocytes is transferred to the neurons via MCTs and acts as energy sources for neurons, helping maintain their function; this system is known as the astrocyte-neuronal lactate shuttle (ANLS; Brooks, 2002). The ANLS has been referred to play a key role in lactate transport and neuronal activity (Pellerin et al., 1998), which is involved in the hippocampal function, such as longterm potentiation and long-term memory as well as endurance exercise capacity (Newman et al., 2011; Suzuki et al., 2011; Lev-Vachnish et al., 2019). Matsui et al. found that a bout of acute moderate-intensity exercise increased hippocampal lactate and ATP levels and decreased brain glycogen concentrations, which was abolished by 1,4-dideoxy-1,4-imino-D-arabinitol (DAB) administration, a glycogenolysis inhibitor, and diminished endurance exercise capacity (Matsui et al., 2017). We thus hypothesized that glycogenolysis inhibition during exercise might also attenuate exercise-induced PGC- $1 \alpha$ and MCTs mRNA expression in the hippocampus. Furthermore, intracerebral DAB administration decreased neuron lactate supply from astrocytes and was deleterious to rat's cognitive function (Suzuki et al., 2011; Matsui et al., 2017). These results suggest that lactate derived from brain glycogenolysis is vital for maintaining brain functions. However, no reports exist on whether lactate derived from brain glycogenolysis contributes to mitochondrial biogenesis after high-intensity exercise.

This study assessed the effects of a single bout of low-, moderate-, or high-intensity treadmill exercise on PGC-1 $\alpha$ mRNA expression and mtDNA copy number in the mouse hippocampus. Next, we examined whether exogenous lactate administration increased hippocampal extracellular lactate concentration and mimicked the effects of high-intensity exercise. 
Then, we examined if exogenous lactate or UK5099, a lactate transporter inhibitor, administered before high-intensity exercise alters mouse hippocampus PGC- $1 \alpha$ mRNA expression and mtDNA copy number as well as BDNF expression. Finally, we examined whether pre-exercise intra-hippocampal injection of DAB affected the mouse hippocampal PGC- $1 \alpha$ and MCTs mRNA expression following high-intensity exercise.

\section{MATERIALS AND METHODS}

\section{Ethical Approval}

Animal use and procedures followed the National Institute of Health guideline and were approved by the Animal Care and Use Committee of Nippon Medical School (approval no. 30-030). Furthermore, we exerted all efforts to minimize animal pain and discomfort.

\section{Animals}

Eight-week-old male ICR mice (weight: 36-38 g; Sankyo Lab, Tokyo, Japan) were used in this study. All mice were housed (5 per cage) in standard transparent mouse cages $(29 \times 18 \times 13 \mathrm{~cm})$ and provided ad libitum access to standard chow (MF; Oriental Yeast Co, Ltd., Tokyo, Japan) and water. Mice selected for surgery were individually housed in the same cages. Room temperature was maintained at $22-24^{\circ} \mathrm{C}$ with $50 \%$ humidity under a $12 \mathrm{~h}$ light/dark cycle (lights on: 08:00-20:00). Following each experiment, all mice were killed by decapitation using a guillotine without anesthesia, which was the most humane method, taking both animal welfare and data quality into consideration (Pierozan et al., 2017).

\section{Treadmill Exercise Protocol}

All mice were subjected to $15 \mathrm{~min}$ of treadmill running at a treadmill running speed of $10-15 \mathrm{~m} / \mathrm{min}$ for three consecutive days during the habituation period. After 3 days of rest following the treadmill habituation period, mice performed treadmill running at low, moderate, or high intensity. The protocol for a single bout of exercise at three intensities is shown in Figure 1A. In brief, low- and moderate-intensity exercise group mice were subjected to a single bout of running on a treadmill at speeds of 10 or $20 \mathrm{~m} / \mathrm{min}$, respectively, for $30 \mathrm{~min}$.

High-intensity exercise consisted of intense intermittent running, including rest, on a treadmill with a gradual increase in speed determined according to the method of Lee et al. (2018) as follows: The mice ran for $1 \mathrm{~min}$ on a treadmill set at a treadmill speed of $20 \mathrm{~m} / \mathrm{min}$ and then rested for $10 \mathrm{~s}$, which was defined as one set. After the mice performed three sets at the same treadmill speed, the speed was increased to $25 \mathrm{~m} / \mathrm{min}$, and the mice again performed three sets. Thus, the treadmill speed continued to rise by $5 \mathrm{~m} / \mathrm{min}$ until exhaustion. Exhaustion was defined as the point at which mice stayed on the grid at the back of the treadmill for a period of $30 \mathrm{~s}$ despite being given mild touches.

\section{Microdialysis}

A stainless steel guide cannula (EICOM CORP, Japan) was implanted stereotaxically into mice dorsal hippocampus $(-1.8 \mathrm{mM}$ anteroposterior, $\pm 1.8 \mathrm{mM}$ mediolateral, $-1.9 \mathrm{mM}$ dorsoventral from the bregma) following a previously reported method (Ishikawa et al., 2016). The mice were allowed to recover for 5 days after surgery. After that, the microdialysis probe (EICOM, CX-4-01) was inserted into the guide cannula approximately $120 \mathrm{~min}$ before the experiment. The probe was perfused with Ringer's solution, containing: $147 \mathrm{mM} \mathrm{NaCl}, 4 \mathrm{mM} \mathrm{KCl}, 2.3 \mathrm{mM} \mathrm{CaCl}$; $\mathrm{pH}$ 6.5.

The microdialysis probe was connected to a commercially available microdialysis liquid-swivel (EICOM) to ensure the free movement of the mice. For measuring hippocampal extracellular lactate concentration, ICR male mice $(n=4)$ were injected with sodium lactate dissolved in PBS ( $\mathrm{pH} 7.4$ ) at a dose of $2 \mathrm{~g} / \mathrm{kg}$ BW by I.P. injection as previously described (Lezi et al., 2013). Another series of ICR male $(n=5)$ mice received the UK5099 $(0.1 \mathrm{ml} ; 50 \mu \mathrm{mol} / \mathrm{kg}$ BW; Tocris, United Kingdom) $30 \mathrm{~min}$ before lactate injection. The flow rate was $1 \mu \mathrm{l} / \mathrm{min}$ allowing the collection of $10 \mu \mathrm{l}$ samples every $10 \mathrm{~min}$. Microdialysis samples were collected into ice-cooled polyethylene tubes (EICOM) using an EFC-96 fraction collector (EICOM). All other microdialysis samples were frozen immediately and stored at $-80^{\circ} \mathrm{C}$ until lactate analysis.

\section{Time Course of Changes in Blood Lactate Concentration After I.P. Injection}

ICR male mice $(n=6)$ were injected with sodium lactate dissolved in PBS ( $\mathrm{pH} 7.4)$ at a dose of $2 \mathrm{~g} / \mathrm{kg}$ BW by I.P. injection. Lactate levels in blood obtained from the tail vein were measured using a portable blood lactate analyzer (Lactate Pro 2, Arkray, Tokyo, Japan) at pre-injection (Pre), 0, 5, 10, 15, 30, 60, and $180 \mathrm{~min}$ after sodium lactate injection.

\section{Experimental Design Experiment 1}

The effects of a single bout of exercise at low, moderate, or high intensity on blood lactate, hippocampal PGC- $1 \alpha$ mRNA, and mtDNA levels are summarized in Figure $\mathbf{1}$.

ICR male mice were divided into four groups: non-exercise (Non-ex, $n=9$ ), low-intensity exercise (Low, $n=8-10$ /group), moderate-intensity exercise (Moderate, $n=8-10 /$ group), and high-intensity exercise (High, $n=8-10$ /group). Mice blood lactate levels were measured before and immediately after every single bout of exercise. Mice were killed 12, 24, 48, and $72 \mathrm{~h}$ after each bout of exercise, and the hippocampus was quickly excised, snap-frozen in liquid nitrogen, and stored at $-80^{\circ} \mathrm{C}$ until analysis.

\section{Experiment 2}

The effects of UK5099 administration on blood lactate, hippocampal mitochondrial biogenesis, MCTs, and BDNF mRNA levels after lactate administration or exercise are summarized in Figures 2-4.

ICR male mice were divided into three groups: control (Cont), vehicle + lactate (Lac), and UK5099+lactate (UK5099+ Lac). UK5099 (0.1 ml; $50 \mu \mathrm{mol} / \mathrm{kg}$ BW; Tocris, 
A

- $\operatorname{Low}(10 \mathrm{~m} / \mathrm{min})$

= Moderate $(20 \mathrm{~m} / \mathrm{min})$

- High (until exhaustion)

0

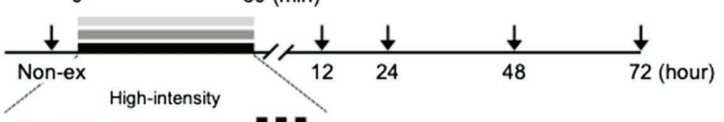

$\downarrow$ Decapitation
V Run 01:00

V Run 01:00
$\nabla$ Rest 00:10
v

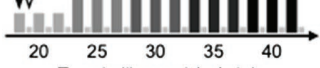

Treadmill speed $(\mathrm{m} / \mathrm{min})$
B

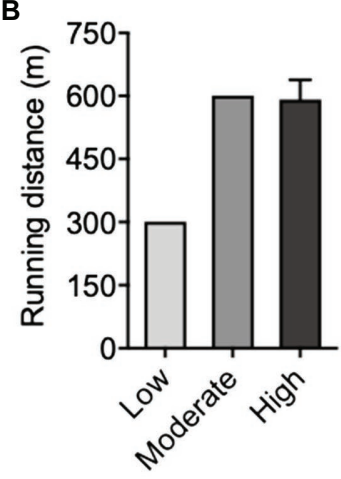

C

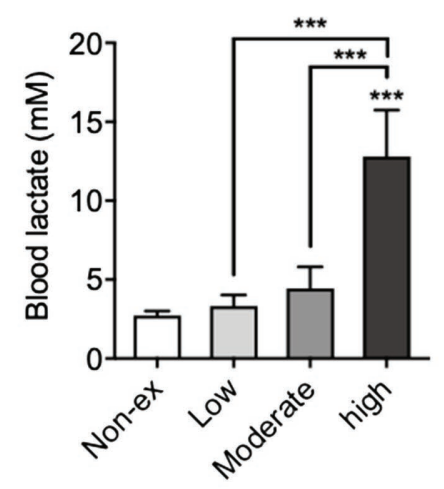

D

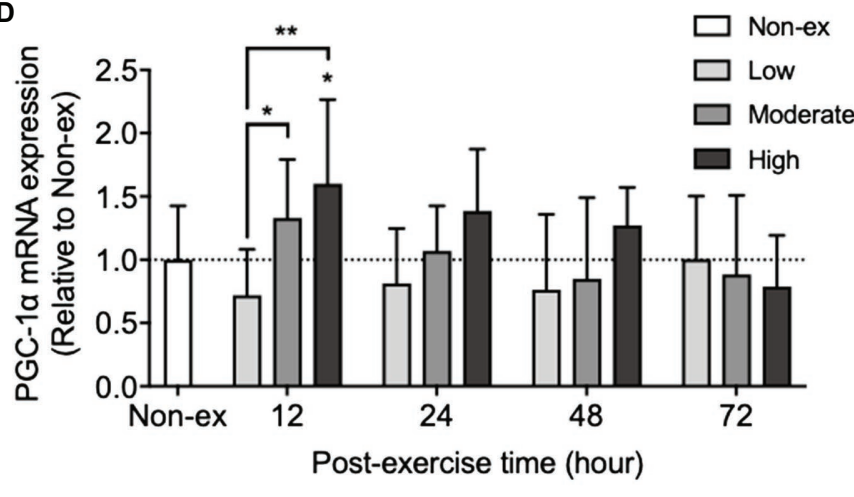

E

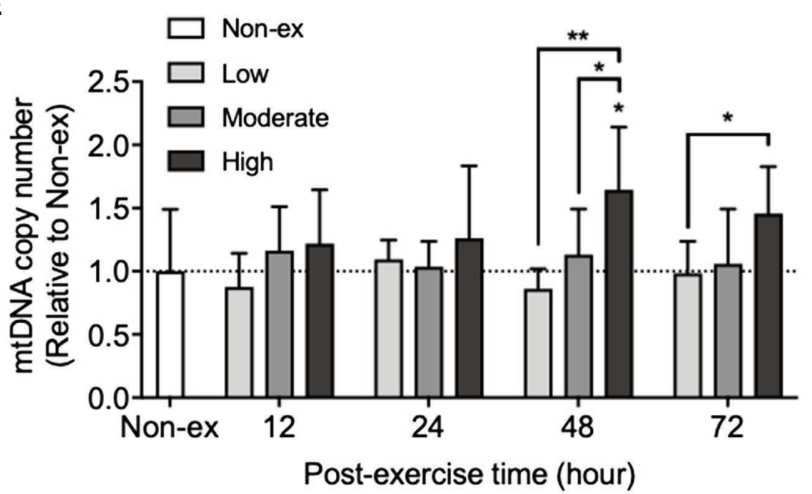

FIGURE 1 | Effects of a single bout of exercise performed at three different intensities on peroxisome proliferator-activated receptor gamma-coactivator $1 \alpha$ (PGC-1 $\alpha$ ) mRNA expression and mitochondrial DNA (mtDNA) copy number in the hippocampus and on blood lactate levels. (A) Protocols for a single bout of exercise. The mice ran on a treadmill at three different intensities: low intensity (low): $10 \mathrm{~m} / \mathrm{min}$ for $30 \mathrm{~min}$; moderate intensity: $20 \mathrm{~m} / \mathrm{min}$ for $30 \mathrm{~min}$ (moderate); and high intensity: the treadmill speed was initially set at $20 \mathrm{~m} / \mathrm{min}$ and gradually increased by $5 \mathrm{~m} / \mathrm{min}$ until the mice were exhausted. (B) Running distance for 30 min at low- and moderate-intensity exercise groups and exhaustion at high-intensity exercise group. (C) Blood lactate levels immediately after a single bout of exercise at three different exercise intensities. (D) Time course changes in PGC-1 $\alpha$ mRNA expression, and (E) mtDNA copy number in the hippocampus at non-exercise (Nonex), 12, 24, 48, and 72h after three different exercise intensities (Non-ex, $n=9$; low, $n=8-10 /$ group; moderate, 8-10/group; high, 8-10/group). All data were presented as the mean \pm SD values. Data were analyzed using one-way ANOVA with Tukey's post-hoc tests or two-way ANOVA with Bonferroni's post-hoc tests. ${ }^{*} p<0.05 ;{ }^{* *} p<0.01$; and ${ }^{* * *} p<0.001$ in comparison with the non-exercise group if not otherwise indicated.

United Kingdom), or a similar amount of DMSO, was I.P. injected $30 \mathrm{~min}$ before lactate injection $(2 \mathrm{~g} / \mathrm{kg})$. Another series of ICR male mice were divided into three groups: Cont, vehicle + a single bout of high-intensity exercise (Ex), and UK5099+a single bout of high-intensity exercise (UK5099+Ex). Lactate levels in blood were measured before lactate administration and exercise and then $15 \mathrm{~min}$ after lactate administration or immediately after exercise. Mice were killed for the measurement of PGC- $1 \alpha$ mRNA expression $12 \mathrm{~h}$ after lactate administration (Cont, $n$ =9; Lac, $n=9$; UK5099 + Lac, $n=8$ ) and exercise (Cont, 

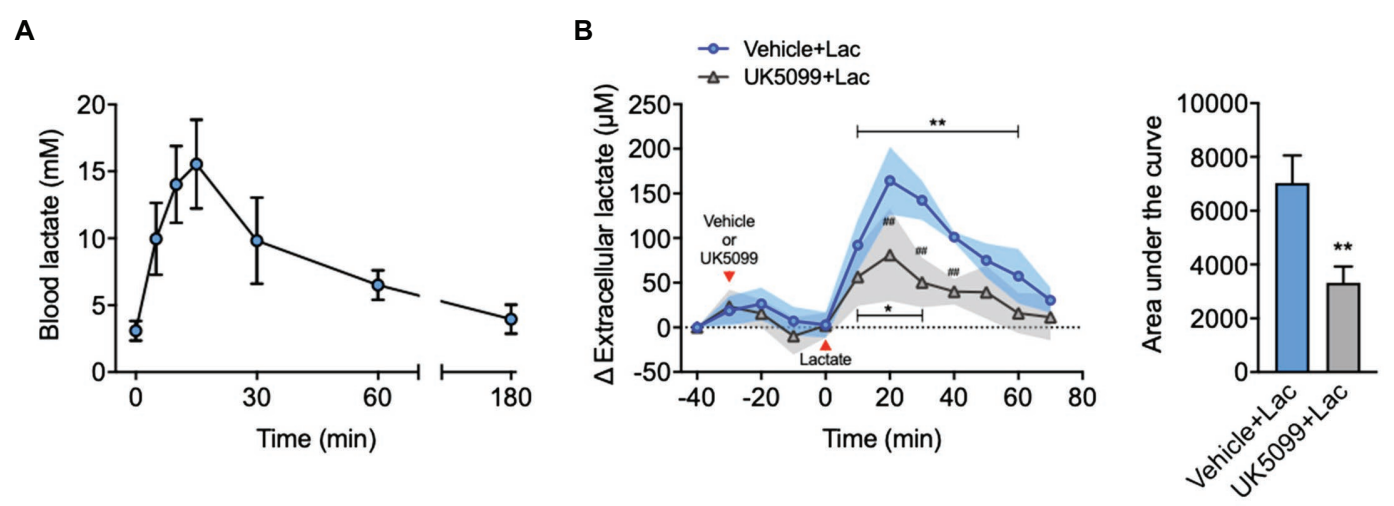

C
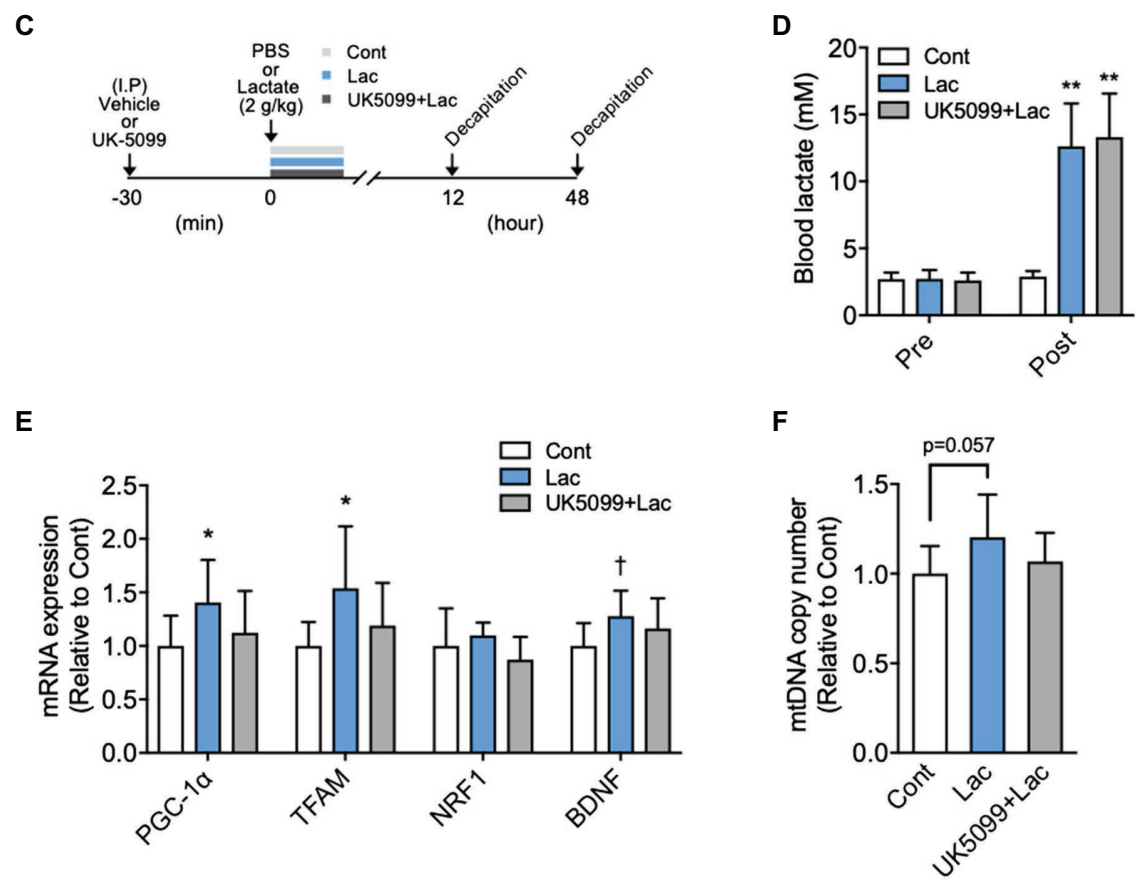

FIGURE 2 | Effects of lactate administration on hippocampal extracellular lactate concentration and mitochondrial biogenesis in the hippocampus. (A) Time course changes in blood lactate concentration after I.P. lactate injection $(2 \mathrm{~g} / \mathrm{kg} ; n=6)$. (B) The hippocampal extracellular lactate concentration changes after I.P. lactate injection with saline or monocarboxylate transporters (MCT) inhibitor (UK5099) administration and area under the curve (Vehicle + Lac, $n=4$; UK5099 + Lac, $n=5$ ).

(C) Experimental design: Mice were injected saline or UK5099 by I.P. injection 30 min before lactate administration. Blood lactate concentration was measured $15 \mathrm{~min}$ after I.P. lactate or saline injection. (D) Blood lactate concentrations before I.P. lactate injection (Pre) and after lactate injection with and without UK5099 (Post). (E) PGC-1 $\alpha$, mitochondrial transcription factor A (TFAM), nuclear respiratory factor1 (NRF1), and brain-derived neurotrophic factor (BDNF) mRNA expression in the hippocampus $12 \mathrm{~h}$ after I.P. lactate injection with and without UK5099 (Cont, $n=9$; Lac, $n=9$; UK5099+Lac, $n=8$ ). (F) mtDNA copy number in the hippocampus $48 \mathrm{~h}$ after I.P. injection of lactate with and without UK5099 (Cont, $n=10$; Lac, $n=10$; UK5099 + Lac, $n=8$ ). All data were presented as the mean \pm SD values. Data were analyzed using two-way ANOVA with Bonferroni's post-hoc tests and unpaired t-test (AUC) (B) and one-way ANOVA with Tukey's post-hoc tests (D-F). ${ }^{*} p<0.05$; ${ }^{* *} p<0.01$; and ${ }^{\dagger} p<0.1$ in comparison with baseline or Cont group and ${ }^{\# \#} p<0.01$ compared to Vehicle + Lac group.

$n=9$; Ex, $n=10$; UK5099 $+\mathrm{Ex}, n=8)$ and for the mtDNA copy number $48 \mathrm{~h}$ after that administration (Cont, $n=10$; Lac, $n=10$; UK5099+Lac, $n=8$ ) and exercise (Cont, $n=10$; Ex, $n=10$; UK5099+Ex, $n=10)$. The hippocampus was quickly excised, snap-frozen in liquid nitrogen, and stored at $-80^{\circ} \mathrm{C}$ until analysis.

\section{Surgery for Intra-Hippocampus Injection}

After the treadmill habituation period, the mice were anesthetized with isoflurane and positioned in a stereotaxic apparatus for steel cannula placement (Narishige Co., Japan).
For intra-hippocampal injection, a small hole was made using a dental drill, and a steel cannula (22-gauge) was inserted into the dorsal hippocampus. The guide cannula was located in the hippocampus $(-1.8 \mathrm{mM}$ anteroposterior, $\pm 1.8 \mathrm{mM}$ mediolateral, and $-1.9 \mathrm{mM}$ dorsoventral from the bregma) following a previously reported method (Ishikawa et al., 2016) and was fixed to the skull using anchor screws (EICOM) and dental cement. After surgery, the mice were individually housed in a warm cage and allowed to recover completely for at least 3 days. 
A

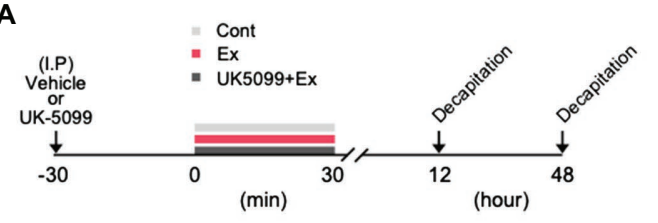

D

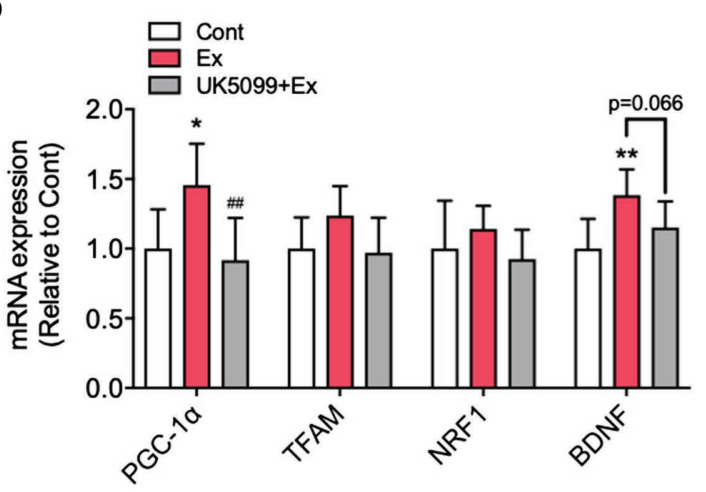

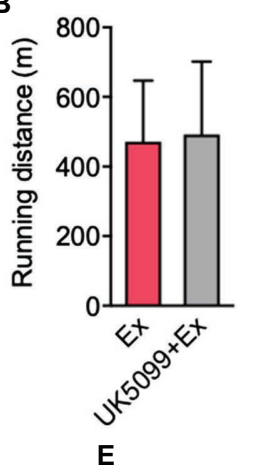

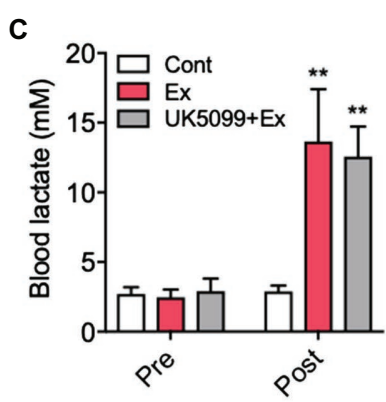

FIGURE 3 | Exercise-induced lactate release increased PGC-1 $\alpha$ mRNA expression and mtDNA copy number in the hippocampus. (A) Experimental design: Mice were injected with saline or UK5099 by I.P. injection $30 \mathrm{~min}$ before a single bout of high-intensity exercise. Blood lactate concentrations were measured immediately after exercise. (B) Running distance to fatigue on a treadmill for mice administered saline (Ex) or UK5099 (UK5099+Ex) before exercise. (C) Blood lactate concentrations before exercise (Pre) and immediately after exercise (Post). (D) PGC-1 $\alpha$, TFAM, NRF1, and BDNF mRNA expression in the hippocampus $12 \mathrm{~h}$ after exercise (Cont, $n=9$; Ex, $n=10$; UK5099+Ex, $n=8$ ). (E) mtDNA copy number in the hippocampus 48h after exercise (Cont, $n=10$; Ex, $n=10$; UK5099+Ex, $n=10$ ). All data were presented as the mean \pm SD values. Data were analyzed using one-way ANOVA with Tukey's post-hoc tests. ${ }^{*} p<0.05$ and ${ }^{* *} p<0.01$ in comparison with Cont group and ${ }^{\#} p<0.05$ and ${ }^{\# \#} p<0.01$ in comparison with Ex group.

A

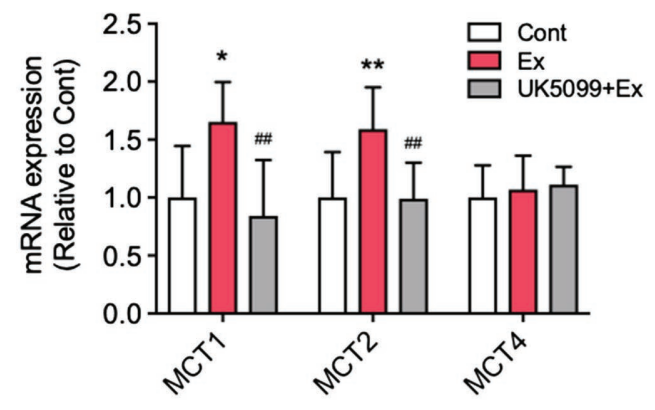

B

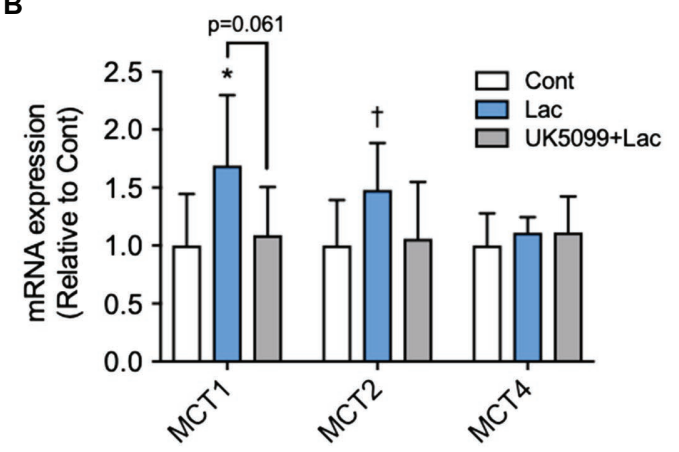

FIGURE 4 | The effects of UK5099 on the hippocampal MCTs and BDNF mRNA expression after lactate administration and high-intensity exercise. Mice were injected with saline or UK5099 by I.P. injection $30 \mathrm{~min}$ before a single bout of high-intensity exercise and lactate administration. MCT1, MCT2, and MCT4 mRNA expression in the hippocampus $12 \mathrm{~h}$ after (A) exercise (Cont, $n=10$; Ex, $n=9$; UK5099+ Ex, $n=9$ ) and (B) I.P. injection of lactate (Cont, $n=9$; Lac, $n=9$; UK5099+Lac, $n=8$ ). All data were presented as the mean \pm SD values. Data were analyzed using one-way ANOVA with Tukey's post-hoc tests. ${ }^{*} p<0.05 ;{ }^{* *} p<0.01$; and ${ }^{\dagger} p<0.1$ in comparison with Cont group and ${ }^{\#} p<0.01$ in comparison with Ex group.

\section{Experiment 3}

The effects of pre-exercise intra-hippocampal injection of DAB on hippocampal glycogen and lactate concentrations and hippocampal PGC-1 $\alpha$ and MCTs mRNA expression are summarized in Figure 5.
After surgery for intra-hippocampal injection, ICR male mice were divided into three groups: control (Cont, $n=6$ ), saline + a single bout of high-intensity exercise group (Ex, $n=6$ ), and $\mathrm{DAB}+\mathrm{a}$ single bout of high-intensity exercise group (DAB + Ex, $n=6)$. 
A

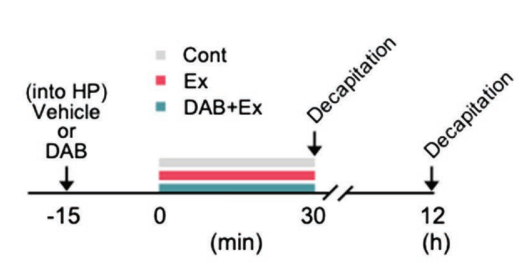

$B$

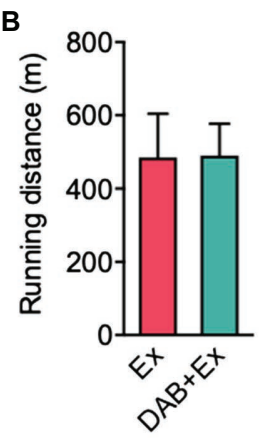

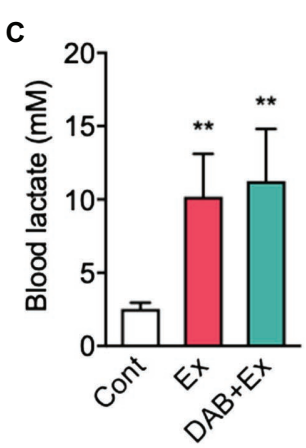

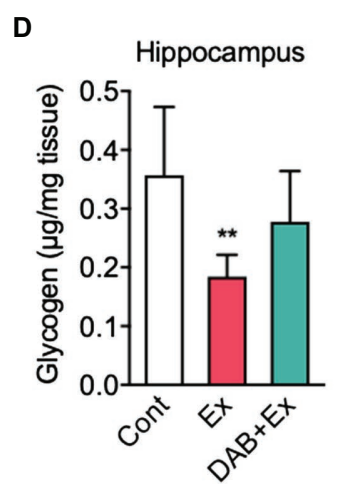

G

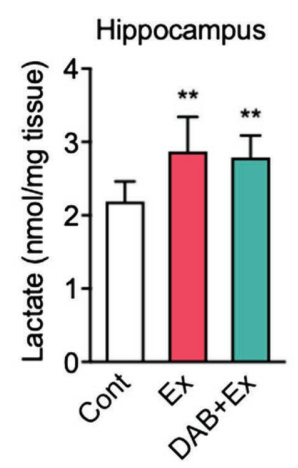

E

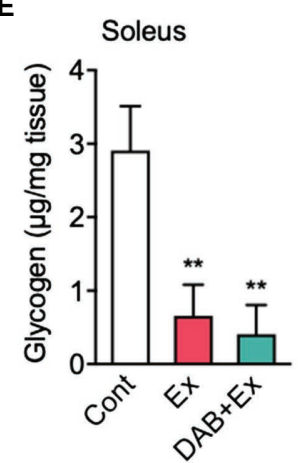

H

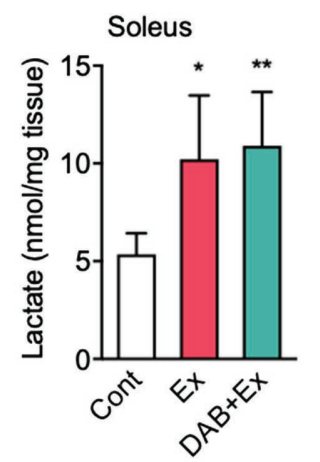

$\mathbf{F}$
I

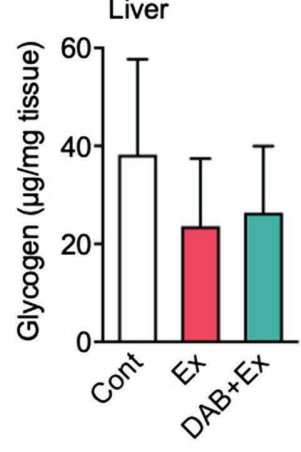

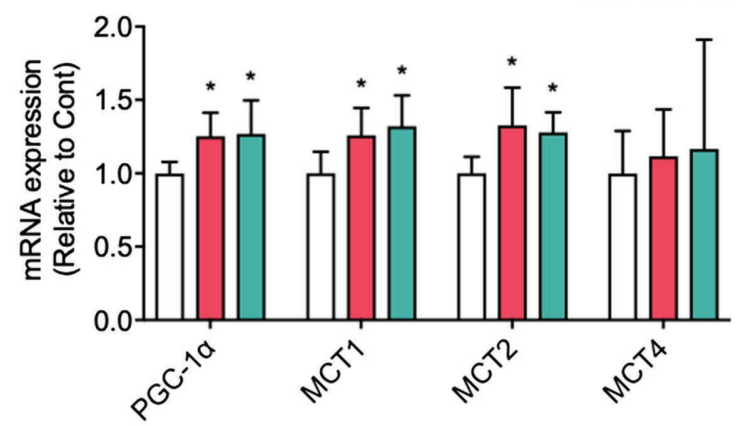

FIGURE 5 | The effects of intra-hippocampal 1,4-dideoxy-1,4-imino-D-arabinitol (DAB) injection before high-intensity exercise on hippocampal glycogen, lactate levels, and PGC-1 $\alpha$, MCTs mRNA expression. (A) Experimental design: Mice were injected saline or DAB by intra-hippocampal injection 15 min before a single bout high-intensity exercise by using a micro-injection pump. (B) Running distance to fatigue on a treadmill for mice administered vehicle (Ex) or DAB (DAB + Ex) before exercise. (C) Blood lactate concentrations immediately after exercise and control. (D) Glycogen levels in the hippocampus, (E) soleus muscle (F) liver, (G) lactate levels in the hippocampus, and $\mathbf{( H )}$ soleus muscle immediately after exercise, with vehicle (Ex) or DAB (DAB + Ex) and control (Cont, $n=6$; Ex, $n=6$; DAB + Ex, $n=6)$. (I) PGC-1 $\alpha$, MCTs mRNA expression in the hippocampus $12 \mathrm{~h}$ after a single bout of high-intensity exercise (Cont, $n=6$; Ex, $n=7 ; \mathrm{DAB}+\mathrm{Ex}, n=7$ ). All data were presented as the mean $\pm S D$ values. Data were analyzed using one-way ANOVA with Tukey's post-hoc tests. ${ }^{*} p<0.05$ and ${ }^{* *} p<0.01$ compared to Cont group.

DAB $(0.25 \mathrm{M}$ in $1 \mu \mathrm{l}$ of $0.9 \%$ saline; Wako, Osaka, Japan) or $1 \mu \mathrm{l}$ of saline was injected into the hippocampus using a syringe pump (Legato 101, KD Scientific). Fifteen minutes after the injection, mice were subjected to a single bout of high-intensity exercise. Mice were killed by decapitation, and the hippocampus, soleus, and liver were excised immediately after exercise, snap-frozen in liquid nitrogen, and stored at $-80^{\circ} \mathrm{C}$ until analysis. Another series of ICR male mice were divided into Cont $(n=6), \operatorname{Ex}(n=6)$, and $\mathrm{DAB}+\mathrm{Ex}(n=6)$. After intra-hippocampal injection of saline or $\mathrm{DAB}$, mice were subjected to exercise. Mice were killed by decapitation, and the hippocampus was collected $12 \mathrm{~h}$ after high-intensity exercise, snap-frozen in liquid nitrogen, and stored at $-80^{\circ} \mathrm{C}$ until analysis.

\section{RNA Extraction and Quantitative Real-Time Polymerase Chain Reaction}

The hippocampus samples of mice were homogenized in TRIzol Reagent (Invitrogen, CA, United States) on ice, and total RNA 
was extracted according to the manufacturer's instructions. Total RNA was quantified using absorption at $260 \mathrm{~nm}$ and the $260: 280 \mathrm{~nm}$ ratio to assess concentration and purity. Complementary DNA was synthesized using $1 \mu \mathrm{g}$ of total RNA in a $20 \mu \mathrm{l}$ reaction with the ReverTra Ace ${ }^{\mathrm{TM}}$ qPCR RT Master Mix with gDNA Remover (FSQ-301; Toyobo, Osaka, Japan) according to the manufacturer's instructions.

Quantitative real-time PCR was performed with the SsoAdvanced Universal SYBR Green Supermix (Bio-Rad) and a CFX Connect Real-time PCR system (Bio-Rad) to quantify the mRNA levels. Glyceraldehyde-3-phosphate dehydrogenase (GAPDH) was used as the endogenous control. The mousespecific primers used were as follows: PGC- $1 \alpha$ : forward 5'-ACCCTGCCATTGTTAAGACC-3', reverse 5'-CTGCTGCT GTTCCTGTTTTC-3'; TFAM: forward 5'-GAAGGGAATGG GAAAGGTAGA-3', reverse 5'-AACAGGACATGGAAAGCA GAT-3'; NRF1: forward 5' - ATCCGAAAGAGACAGCAGACA-3', reverse $5^{\prime}$ - TGGAGGGTGAGATGCAGAGTA-3'; MCT1: forward $5^{\prime}$-TTGTCTGTCTGGTTGCGGCTTGATCG-3' ${ }^{\prime}$, reverse $5^{\prime}$-GCC CAAGACCTCCAATAACACCAATGC-3'; MCT2: forward 5'-CACCACCTCCAGTCAGATCG-3' ${ }^{\prime}$, reverse $5^{\prime}$-CTCCCACTA TCACCACAGGC-3'; MCT4: forward 5'-TCAATCATGGTGCT GGGACT-3', reverse $5^{\prime}$-TGTCAGGTCAGTGAAGCCAT-3'; BDNF: forward $5^{\prime}$-TGCAGGGGCATAGACAAAAGG-3' ${ }^{\prime}$, reverse $5^{\prime}$-CTTATGAATCGCCAGCCAATTCTC-3'; and GAPDH forward 5'-CATCACTGCCACCCAGAAGA-3' ${ }^{\prime}$, reverse $5^{\prime}$-ATG TTCTGGGCAGCC- $3^{\prime}$. The $2^{-\Delta \Delta C}$ method was used to analyze relative mRNA expression values (Livak and Schmittgen, 2001). Sample analysis for each gene was performed in duplicate.

\section{mtDNA Copy Number}

For quantifying hippocampal mtDNA, total DNA was extracted from the hippocampus using the phenol-chloroform method, as described previously (Mikami et al., 2021). First, the hippocampal tissue $(\sim 20 \mathrm{mg})$ was dissolved in $200 \mu$ l of lysate buffer containing $10 \mathrm{mM}$ Tris- $\mathrm{HCl}(\mathrm{pH} 8.0), 150 \mathrm{mM} \mathrm{NaCl}$, $10 \mathrm{mM}$ EDTA (pH 8.0), 0.1\% SDS, and $2.5 \%$ proteinase K; next, it was vortexed, incubated at $56^{\circ} \mathrm{C}$ for $90 \mathrm{~min}$, and centrifuged at $2,000 \mathrm{~g}$ for $10 \mathrm{~min}$.

The supernatant was mixed with an equal volume of phenol/ chloroform/isoamyl alcohol, vortexed, and centrifuged at 2,000 $\times g$ for $10 \mathrm{~min}$. Then, the supernatant obtained was mixed with two volumes of $100 \%$ ethanol by slow inversion and centrifuged at $10,000 \times g$ for $10 \mathrm{~min}$. After the supernatant was removed, the precipitate was dissolved in $70 \%$ ethanol by slow inversion and centrifuged at $10,000 \times \mathrm{g}$ for $10 \mathrm{~min}$.

Subsequently, after the supernatant obtained was removed, the precipitate was left for $5 \mathrm{~min}$ at room temperature, dissolved in Tris-EDTA (TE) buffer ( $\mathrm{pH} 8.0$ ), and stored at $-20^{\circ} \mathrm{C}$ until analysis. DNA concentration and purity were analyzed using absorption at $260 \mathrm{~nm}$ and the $260: 280 \mathrm{~nm}$ absorption ratio, respectively.

Quantitative real-time PCR (10 ng DNA) was performed with the SsoAdvanced Universal SYBR Green Supermix. 18S ribosomal RNA (18S rRNA) was used as the nuclear DNA (nDNA) control. The mtDNA and nDNA primers used were as follows: COX I: forward 5'-TGATTCCCATTATTTT CAGGCTTC-3', reverse 5' ${ }^{\prime}$-ACTCCTACGAATATGATGGCG AA-3'; and $18 \mathrm{~S}$ rRNA: forward 5'-CGCCGCTAGAG GTGAAATTC- ${ }^{\prime}$, reverse 5'-CTTGGCAAATGCTTTCGCTC-3'. The $2^{-\Delta \Delta C}{ }_{t}$ method was used to analyze the relative mtDNA to nDNA copy number ratio (Livak and Schmittgen, 2001). Sample analysis for each gene was performed in duplicate.

\section{Lactate and Glycogen Concentrations in Tissues}

For measuring lactate and glycogen concentrations, the mice were killed immediately after a single bout of high-intensity exercise, and the hippocampus, muscle, and liver tissues were obtained. Glycogen and lactate levels in these tissues were colorimetrically measured using Glycogen Assay Kit II (ab169558; Abcam, Cambridge, United Kingdom) and L-Lactate Assay Kit (MAK064; Sigma, United Kingdom), respectively, according to the manufacturer's protocols. Samples were deproteinized with a $10 \mathrm{kDa}$ MWCO spin filter to remove lactate dehydrogenase.

\section{Statistical Analysis}

Data are expressed as mean \pm SD and were analyzed using GraphPad Prism version 8.4.1 (MDF Co, Ltd., Tokyo, Japan). Group comparisons were performed using one-way ANOVA with Tukey's post-hoc tests or two-way ANOVA with Dunnett's and Bonferroni's post-hoc tests. In addition, comparisons of two groups were performed using an unpaired Student's $t$-test. The differences between groups were considered statistically significant at $p<0.05$.

\section{RESULTS}

\section{Time Course of Changes in Hippocampal PGC-1 $\alpha$ mRNA Levels and mtDNA Copy Number Following a Single Bout of Exercise}

We examined the time course changes in hippocampal PGC-1 $\alpha$ mRNA and mtDNA copy number after a single bout of exercise at three different intensities (Figure 1A). Low- and moderateintensity exercise groups ran 300- and 600-meter distances in $30 \mathrm{~min}$, respectively. Although running distance until exhaustion in the high-intensity exercise group (time to exhaustion: $26.1 \pm 0.37 \mathrm{~min}$, including rest) did not differ from the distance covered by the moderate-intensity exercise group (Figure 1B), the blood lactate concentrations immediately after high-intensity exercise were significantly higher than those in the other two groups $\left(F_{3,36}=80.35, p<0.0001\right.$; Figure $\left.1 C\right)$. Hippocampal PGC- $1 \alpha$ mRNA levels did not significantly change at any time point after the low-intensity exercise. At $12 \mathrm{~h}$ after moderate- and high-intensity exercises, the expression levels were significantly higher than those of the low-intensity exercise group. Compared with the non-exercise group, PGC-1 $\alpha$ mRNA levels significantly increased only in the high-intensity exercise group $\left(F_{2,127}=5.26\right.$, $p=0.0065$; Figure 1D). The mtDNA copy number significantly 
increased $48 \mathrm{~h}$ after a single bout of high-intensity exercise compared with the non-exercise, low-, and moderate-intensity exercise groups $\left(F_{2,129}=10.70, p<0.0001\right)$. However, the low- or moderate-intensity exercise groups did not show any increase compared to the non-exercise group (Figure 1E). These results indicated a relationship between the increase in blood lactate and hippocampal PGC-1 $\alpha$ mRNA levels observed after highintensity exercise.

\section{The Effects of a Single Administration of Lactate on Hippocampal Extracellular Lactate Concentrations and Mitochondrial Biogenesis}

Blood lactate levels reached $15.5 \pm 1.36 \mathrm{mM}$ at $15 \mathrm{~min}$ following I.P. lactate injection, comparable to that observed immediately after high-intensity exercise (Figure 2A), and returned to baseline levels at $180 \mathrm{~min}$ after injection. Baseline hippocampal extracellular lactate concentrations did not differ between the two groups (Vehicle + Lac, 99.1 \pm 3.71 ; UK5099 + Lac, $107.3 \pm 2.44 \mu \mathrm{m} ; p=0.11)$. The extracellular lactate concentration in the hippocampus was significantly increased following I.P. lactate administration after $10 \mathrm{~min}$ and remained high until $60 \mathrm{~min}$, and then returned to baseline.

At 20 min after lactate injection, hippocampal extracellular lactate concentration increased by $\sim 160 \mu \mathrm{m}$ from baseline. Lactate-derived elevation in extracellular lactate concentration was significantly suppressed by UK5099 injection $\left(F_{1,82}=44.00\right.$, $p<0.0001$; Figure 2B). The decrease in hippocampal extracellular lactate via UK5099 administration was also proved by the results of the area under the curve analysis (Figure 2B). We administered vehicle or UK5099 to the mice $30 \mathrm{~min}$ before lactate injection (Figure 2C). We observed no difference in the increased blood lactate levels between $\mathrm{Lac}$ and Lac + UK5099 group, which were equal to those observed immediately after high-intensity exercise (Figure 2D). The mice injected with lactate showed significantly higher PGC- $1 \alpha\left(F_{2,23}=3.33, p=0.051\right)$ and TFAM $\left(F_{2,23}=3.27, p=0.058\right)$ mRNA, but not significantly higher in BDNF mRNA $\left(F_{2,23}=2.61, p=0.098\right)$. Besides, these mice tended to have a higher mtDNA copy number $\left(F_{2,25}=2.98\right.$, $p=0.068$ ) in the hippocampus than the Cont group after injection. However, these changes were not observed in mice injected UK5099 (Figures 2E,F).

\section{The Effects of UK5099 Administration Before Exercise on Hippocampal Mitochondrial Biogenesis}

Mice were injected vehicle or UK5099 before a single bout of high-intensity exercise (Figure 3A). Ex and UK5099+Ex group showed a similar running distance to fatigue (Figure 3B) and blood lactate levels immediately after exercise (Figure 3C). However, the Ex group showed significantly higher hippocampal PGC- $1 \alpha\left(F_{2,24}=9.67, p<0.001\right)$ and BDNF mRNA $(12 \mathrm{~h}$ after exercise; $\left.F_{2,24}=7.89, p<0.01\right)$, and hippocampal mtDNA copy number $\left(48 \mathrm{~h}\right.$ after exercise; $F_{2,27}=5.24, p<0.05$ ) than the Cont group (Figures 3D,E). In contrast, the UK5099+Ex group showed significantly lower PGC- $1 \alpha$ mRNA and mtDNA levels than the Ex group (Figures 3D,E). However, there was no significant difference in downstream regulators of mitochondrial biogenesis, TFAM, and NRF1 mRNA among the groups (Figure 3D).

\section{The Effects of UK5099 on Hippocampal MCTs mRNA Expression After Lactate Administration and Exercise}

We found that MCT1 $\left(F_{2,24}=8.12, p<0.01\right)$ and MCT2 $\left(F_{2,24}=7.43\right.$, $p<0.01)$ mRNA expression in the hippocampus significantly increased in the Ex group than in the Cont group, whereas these increments were abolished by UK5099 administration before exercise (Figure 4A). After lactate administration, only MCT1 $\left(F_{2,23}=4.59, p<0.05\right)$ increased significantly, and MCT2 $\left(F_{2,23}=2.94, p=0.075\right)$ tended to be higher than that in the Cont group; however, the increment of those genes was not observed in mice injected UK5099 compared with the Cont group (Figure 4B). On the other hand, no changes were observed in MCT4 mRNA expression after exercise and lactate administration (Figures 4A,B).

\section{The Effects of Glycogenolysis Inhibition During Exercise on Hippocampal Lactate and the Expression of PGC-1 $\alpha$ and MCTs mRNA}

Mice received a micro-injection of $\mathrm{DAB}$ or vehicle into the hippocampus, and $15 \mathrm{~min}$ later, mice were subjected to a single bout of high-intensity exercise (Figure 5A). Mice injected with vehicle or $\mathrm{DAB}$ showed a similar running distance to fatigue (Figure 4B). Immediately after exercise, the blood lactate levels were similar with and without $\mathrm{DAB}$ injection $\left(F_{2,17}=19.02\right.$, $p<0.0001$; Figure 5C). The hippocampal glycogen levels significantly decreased in the Ex group compared with the Cont mice. Still, significant alterations were not noted in the $\mathrm{DAB}+\mathrm{Ex}$ group, indicating the pre-exercise micro-injection of $\mathrm{DAB}$ inhibited hippocampal glycogenolysis during exercise $\left(F_{2,15}=6.03, p<0.05\right.$; Figure 5D). The glycogen concentration in mice soleus muscles from the $\mathrm{Ex}$ and $\mathrm{DAB}+\mathrm{Ex}$ groups were decreased compared with Cont group $\left(F_{2,15}=48.01\right.$, $p<0.0001$; Figure 5E). However, liver glycogen concentration did not significantly decrease in either group during a single short-term, high-intensity exercise for approximately $30 \mathrm{~min}$ (Figure 5F).

Unexpectedly, despite the inhibition of hippocampal glycogenolysis during exercise by $\mathrm{DAB}$, hippocampal lactate levels immediately after exercise showed a similar significant increase in both $\mathrm{Ex}$ and $\mathrm{DAB}+\mathrm{Ex}$ groups. These results indicated that the increase in hippocampal lactate during highintensity exercise could much depend on lactate uptake from the circulating blood than intra-hippocampal lactate production by astrocyte glycolysis $\left(F_{2,15}=6.57, \quad p<0.01\right.$; Figure 5G). Additionally, in the soleus muscle, lactate levels noted immediately after a single bout of high-intensity exercise were significantly higher in both exercise groups than in the Cont group $\left(F_{2,15}=8.52\right.$, 
$p<0.01$; Figure 5H). Furthermore, the exercise groups with or without $\mathrm{DAB}$ injection showed a similar higher PGC-1 $\alpha$ $\left(F_{2,17}=5.29, p<0.05\right)$, MCT1 $\left(F_{2,17}=5.58, p<0.05\right)$, and MCT2 mRNA expression $\left(F_{2,17}=5.88, p<0.05\right)$ in the hippocampus than the Cont group, but MCT4 mRNA expression did not differ among the three groups (Figure 5I). These results suggested that the single short-term, high-intensity exercise used in this study rapidly increases lactate release from skeletal muscle into blood, which is pivotal to increase hippocampal lactate concentration and might contribute to enhance the induction of PGC- $1 \alpha$ and MCTs mRNA expression in the hippocampus.

\section{DISCUSSION}

Regular exercise training enhances skeletal muscle and hippocampal PGC- $1 \alpha$ mRNA and mtDNA copy number (Zhang et al., 2012; Halling et al., 2019). Six weeks of HIIT accompanied by increased blood and hippocampal lactate concentrations has been reported to increase hippocampal expression of mitochondrial biogenesis-related genes PGC-1 $\alpha$, NRF2, and mtDNA copy number ( $\mathrm{Hu}$ et al., 2021). The effects of regular exercise reflect an accumulation of physiological adaptations produced by bouts of high-intensity exercise. Thus, it is essential to understand the beneficial effects of a single bout of highintensity exercise and elucidate the mechanisms underlying their effects to produce better high-intensity exercise training strategies. However, the effects of acute high-intensity exercise on hippocampal mitochondrial biogenesis are unclear.

In the current study, an increase in hippocampal PGC- $1 \alpha$ mRNA expression was observed $12 \mathrm{~h}$ after exercise. An increase in hippocampal mtDNA copy number followed $48 \mathrm{~h}$ later, and its increment depended on exercise intensity. Running time to exhaustion $(26.1 \pm 0.37 \mathrm{~min})$ is slightly below in the highintensity exercise group compared to the low- and moderateintensity exercise groups $(30 \mathrm{~min})$; running distance in the high-intensity group did not differ from that of the moderateintensity exercise group. However, the blood lactate concentrations immediately after exercise and post-exercise hippocampal mitochondrial biogenesis significantly differed between the three exercise groups. These results are consistent with the previous reports that $20 \mathrm{~min}$ of a single bout of high-intensity exercise induced the activation of skeletal muscle mitochondrial transcription (Hoshino et al., 2015), and exercise intensity affects skeletal muscle PGC-1 $\alpha$ protein levels (Terada et al., 2005; Tadaishi et al., 2011). Moreover, the present results are consistent with the results of the human study, which indicated that a high-intensity interval cycle ergometer for a total duration of $20 \mathrm{~min}$ showed higher BDNF serum concentration levels than at rest and moderate-intensity exercise group in the human study (Saucedo Marquez et al., 2015).

A blood lactate concentration $>12 \mathrm{mM}$ was required to increase hippocampal PGC-1 $\alpha$ mRNA and mtDNA copy number. In contrast, low- or moderate-intensity exercise correlated with 3-4 $\mathrm{mM}$ blood lactate concentration, which did not increase the hippocampal PGC- $1 \alpha$ mRNA and mtDNA copy number. These results are consistent with previous findings that exercise intensity above the LT increased PGC- $1 \alpha$ mRNA expression in human skeletal muscle but that below the LT did not (Tobina et al., 2011). Thus, these results suggested that elevated blood lactate induced by high-intensity exercise above the LT would contribute to the induction of mtDNA copy number through PGC- $1 \alpha$ expression in the hippocampus.

To our knowledge, the current study is the first to show that an increase in mitochondrial biogenesis in the brain, especially the hippocampus, depends on exercise intensity in the same manner as seen in skeletal muscle. In contrast, a single bout of low- or moderate-intensity exercise did not affect mitochondrial biogenesis in the hippocampus. Thus, single bouts of low- or moderate-intensity exercise are not likely to induce hippocampal mitochondrial biogenesis, suggesting that these exercises would need to be regularly repeated over 4 weeks to promote hippocampal mitochondrial biogenesis (Steiner et al., 2011; Zhang et al., 2012).

Brain cell MCTs transport lactate across the BBB (El Hayek et al., 2019), which is enhanced during exercise (Quistorff et al., 2008; van Hall et al., 2009). Acute (Takimoto and Hamada, 2014) and chronic exercise (El Hayek et al., 2019) above LT enhances MCT expression in the hippocampus, enhancing cognitive function by increasing BDNF expression through the induction of PGC-1 $\alpha$ (El Hayek et al., 2019). Besides, Overgaard et al. (2012) indicated that the brain uptakes lactate from the blood and releases lactate into the blood concomitantly, and that net lactate uptake is a plus, and net brain lactate uptake is increased by the increase in circulating blood lactate level during high-intensity exercise. Based on these data, we predicted that some of the blood lactate increased by a single bout of high-intensity exercise or lactate administration would be taken up into the brain via MCTs, where it would promote PGC- $1 \alpha$ expression, followed by mitochondrial biogenesis. To test this hypothesis, we examined hippocampal extracellular lactate concentration by using in vivo microdialysis in the presence and absence of UK5099, a potent MCT1-4 inhibitor, after lactate injection. In this experiment, to eliminate the influence of lactate production derived from astrocytes glycogenolysis, which would be expected to occur during high-intensity exercise, I.P. lactate administration and microdialysis were performed using the resting instead of the exercised mice.

We found that the hippocampal extracellular lactate concentration increased following lactate injection, consistent with previous studies (Machler et al., 2016; Carrard et al., 2018). However, this lactate concentration increase was suppressed by UK5099 administration, indicating that MCT inhibition prevents lactate transport from the blood into hippocampal extracellular space. Furthermore, UK5099 administration also suppressed lactate-induced increases in hippocampal PGC-1 $\alpha$ and TFAM mRNA, and mtDNA copy number.

The results demonstrate that high-intensity exercise or lactate administration increases hippocampal extracellular lactate concentration, which could induce hippocampal PGC- $1 \alpha$ mRNA expression and increase mtDNA copy number. Moreover, hippocampal BDNF mRNA expression was also increased after a single bout of high-intensity exercise, which was consistent with a previous study showing that increased PGC-1 $\alpha$ led to 
the induction of BDNF expression (Wrann et al., 2013; Mikami et al., 2021). In addition, the lactate-induced hippocampal BDNF expression was suppressed by injecting MCT1/2 inhibitor, AR-C155858 (El Hayek et al., 2019). However, the present study does not elucidate how the increased hippocampal lactate upregulated PGC-1 $\alpha$ and BDNF mRNA expression. Yang et al. showed that exposure of neurons to lactate modified the intracellular NADH/NAD ratio, promoted N-methyl-D-aspartate (NMDA) receptor activity and its downstream signaling cascade Erk1/2 (Yang et al., 2014). The activating of the NMDA receptors caused an increase in intracellular $\mathrm{Ca}^{2+}$ concentration, thereby inducing the gene expression of PGC-1 $\alpha$ (Luo et al., 2009). We hypothesize that lactate taken up from blood into the brain could have altered intracellular NADH/NAD ratio and could have triggered changed mRNA expressions related to mitochondrial biogenesis. Further studies are necessary to prove our hypothesis.

Exogenous lactate administration increased blood lactate concentration, induced hippocampal PGC-1 $\alpha$ and MCT mRNA expression, and increased mtDNA copy number, similar to high-intensity exercise. These results indicated that systemic administration of lactate mimics the effect of high-intensity exercise on hippocampal mitochondria biogenesis. However, a single lactate administration was insufficient to increase MCT2 and BDNF mRNA, and mtDNA copy number to the same extent as a single bout of high-intensity exercise.

We speculate that the differences in hippocampal mRNA expression and mtDNA copy number between exogenous lactate administration and bouts of high-intensity exercise may result from the production of myokines and other factors induced by high-intensity exercise but not by exogenous lactate administration. Irisin, a myokine released from skeletal muscle, is transferred to the brain and induces hippocampal PGC-1 $\alpha$ and BDNF expression (Wrann et al., 2013; Azimi et al., 2018; Lourenco et al., 2019). In the future studies, we plan to investigate the effect of lactate administration on myokines in the circulating blood.

The role of lactate produced by astrocytic glycolysis in mediating memory processes (Descalzi et al., 2019) and exercise endurance capacity has recently been characterized (Machler et al., 2016; Matsui et al., 2017). The glycogen in astrocytes is broken down and metabolized to lactate, shuttled to neurons via MCT2, and acts as an energy source in nerve cells (Pellerin et al., 1998; Brooks, 2020). Inhibiting hippocampal glycogenolysis via $\mathrm{DAB}$ injection impaired memory and decreased endurance exercise capacity, indicating that the lactate supplied by astrocytes to neurons is critical for regulating memory processing (Suzuki et al., 2011) and maintaining endurance capacity (Matsui et al., 2017). We speculate that glycogen-derived lactate released during exercise might mediate the promotion of hippocampal mitochondrial biogenesis after high-intensity exercise.

Our results showed that compared with mice injected with saline, DAB injection before exercise inhibited hippocampal glycogenolysis after exercise; however, hippocampal lactate concentration following high-intensity exercise was elevated in the presence or absence of DAB. Moreover, hippocampal
PGC-1 $\alpha$, MCT1, and MCT2 mRNA expression following highintensity exercise were unaffected by $\mathrm{DAB}$ injection before exercise. These results indicate that the lactate derived from hippocampal glycogenolysis during high-intensity exercise does not promote hippocampal PGC- $1 \alpha$, MCT1, and MCT2 mRNA expression. This was inconsistent with the previous findings that lactate derived from astrocytic glycogenolysis is vital for cognitive memory and regulating exercise performance. Based on these results, although a possible effect of brain glycogenderived lactate release cannot be ruled out, we speculate that the induction of hippocampal PGC- $1 \alpha$, MCT1, and MCT2 mRNA expression after exhaustive and short-term exercise is attributable to the marked increase in the lactate taken into the brain from the blood, rather than from astrocytic glycogenolysis.

The following results support our speculation; (1) hippocampal extracellular lactate, taken up from blood into the brain, was suppressed by MCT inhibitors, followed by a marked decrease in PGC- $1 \alpha$, MCT1, and MCT2 mRNA expression; (2) the inhibition of hippocampal glycogenolysis by DAB did not affect PGC-1 $\alpha$, MCT1, and MCT2 mRNA expression. The type of exercise used in the present study was short-term and exhaustive; if the exercise were different, the contribution of lactate derived from brain glycogenolysis on gene expression related to mitochondrial biogenesis would be altered. Further study is necessary to investigate the contribution of lactate, which is incorporated from circulating blood or produced from brain glycogenolysis, and the beneficial effect of different types of exercises on brain function. Our results provide a helpful strategy to enhance brain function via high-intensity exercise training, which may contribute to developing exercise programs in human subjects.

\section{Limitations}

In the present study, we used only male mice, based on results from a previous study using male mice that showed that intermittent intense exercise prevents the stress-induced decline of cognitive function and suppresses the decrease in neurons survival (Lee et al., 2018). Thus, we did not compare the difference in hippocampal mitochondrial biogenesis after exercise between male and female mice. Therefore, the sex difference in mitochondrial biogenesis is not clarified. However, it has been reported that there are no differences in heart mitochondrial activity between sexes in young mice (6 weeks old). On the other hand, it has been reported that female mice have a higher brain mitochondrial respiratory and reserve function than male mice because of lower $\mathrm{H}_{2} \mathrm{O}_{2}$ production in female cardiac and brain tissue (Khalifa et al., 2017). Besides, it has been reported that, in old age mice ( 22 months old), the gene expression of key regulators of mitochondrial biogenesis (PGC-1 $\alpha$, Sirtuin1, and NRF2) and mitochondrial activity in the brain was significantly lower in females than males (Zawada et al., 2015). Until now, the sex differences in the effects of exercise on brain mitochondrial biogenesis have not been clarified. Therefore, further studies to examine whether mitochondrial biogenesis induced by high-intensity exercise is different between the sexes are needed. 
This study focused only on lactate and did not consider stress-related factors, such as cortisol, (nor) epinephrine, and corticosterone. High-intensity exercise, such as the one used in the present study, increases the stress-related factors mentioned above. Chronic stress has previously been shown to have undesirable effects on brain functions. On the other hand, some studies have reported that acute stress, unlike chronic stress, has a beneficial effect on brain functions. For example, acute and short-term stress or single doses of corticosterone significantly increase hippocampal cell proliferation (Kirby et al., 2013). Additionally, acute stress increases the circulating corticosterone levels, leading to the activation of glucocorticoid receptors and subsequently provoking the synthesis and BDNF expression (Yang et al., 2004). Based on these results, stressrelated factors might have also contributed to the increased mitochondrial biogenesis observed in this study. However, we did not examine the effects of high-intensity exercise-induced mitochondria biogenesis on stress-related factors such a corticosterone plasma concentration and PGC- $1 \alpha$ alteration in the presence of corticosterone antagonist. Therefore, in addition to the effect of blood lactate on mitochondria biogenesis, the study of stress-related factors on increased mitochondria biogenesis after high-intensity exercise is necessary for the future.

\section{CONCLUSION}

Our results show that a single bout of exercise above the LT intensity enhanced hippocampal mitochondrial biogenesis. A single injection of exogenous lactate increased hippocampal extracellular lactate concentration, which partially mimicked the effects of a single bout of high-intensity exercise. Additionally, the UK5099 administration abolished the increase in hippocampal extracellular lactate concentration. However, DAB did not affect hippocampal lactate, PGC- $1 \alpha$, and MCT mRNA concentration despite inhibiting hippocampal glycogenolysis. Therefore, the lactate released into the blood from skeletal muscle during high-intensity exercise may be a crucial stimulator for hippocampal mitochondria biogenesis. These data improve our

\section{REFERENCES}

Azimi, M., Gharakhanlou, R., Naghdi, N., Khodadadi, D., and Heysieattalab, S. (2018). Moderate treadmill exercise ameliorates amyloid-beta-induced learning and memory impairment, possibly via increasing AMPK activity and upregulation of the PGC-1alpha/FNDC5/BDNF pathway. Peptides 102, 78-88. doi: $10.1016 /$ j.peptides.2017.12.027

Billat, V. L., Mouisel, E., Roblot, N., and Melki, J. (2005). Inter- and intrastrain variation in mouse critical running speed. J. Appl. Physiol. 98, 1258-1263. doi: 10.1152/japplphysiol.00991.2004

Brooks, G. A. (2002). Lactate shuttles in nature. Biochem. Soc. Trans. 30, 258-264. doi: 10.1042/bst0300258

Brooks, G. A. (2020). Lactate as a fulcrum of metabolism. Redox Biol. 35:101454. doi: 10.1016/j.redox.2020.101454

Carrard, A., Elsayed, M., Margineanu, M., Boury-Jamot, B., Fragniere, L., Meylan, E. M., et al. (2018). Peripheral administration of lactate produces antidepressant-like effects. Mol. Psychiatry 23, 392-399. doi: 10.1038/mp.2016.179

Descalzi, G., Gao, V., Steinman, M. Q., Suzuki, A., and Alberini, C. M. (2019). Lactate from astrocytes fuels learning-induced mRNA translation understanding of the effects of high-intensity exercise and may be a basis for further clinical or athletic applications.

\section{DATA AVAILABILITY STATEMENT}

The raw data supporting the conclusions of this article will be made available by the authors, without undue reservation.

\section{ETHICS STATEMENT}

The animal study was reviewed and approved by the Animal Care and Use Committee of Nippon Medical School (approval no. 30-030).

\section{AUTHOR CONTRIBUTIONS}

JP and TM conceived and designed experiments, interpreted the results of experiments, and drafted the manuscript. JP, JK, and TM performed experiments and analyzed data. JP prepared figures. All authors have approved to submit the final version manuscript.

\section{FUNDING}

This study was supported by a Grant-in-Aid for Early-Career Scientists (19K20051) from the Japan Society for the Promotion of Science (JSPS).

\section{ACKNOWLEDGMENTS}

We would like to thank Dr. H. Suzuki, Dr. H. Ozawa (Nippon Medical School) for the critical review and discussion of the manuscript, and Dr. S. Ohta (Juntendo University) for technical support. We would like to thank Editage (www.editage.com) for English language editing.

in excitatory and inhibitory neurons. Commun. Biol. 2:247. doi: 10.1038/ s42003-019-0495-2

El Hayek, L., Khalifeh, M., Zibara, V., Abi Assaad, R., Emmanuel, N., Karnib, N., et al. (2019). Lactate mediates the effects of exercise on learning and memory through SIRT1-dependent activation of hippocampal brain-derived neurotrophic factor (BDNF). J. Neurosci. 39, 2369-2382. doi: 10.1523/JNEUROSCI.1661-18.2019

Freitas, D. A., Rocha-Vieira, E., Soares, B. A., Nonato, L. F., Fonseca, S. R., Martins, J. B., et al. (2018). High intensity interval training modulates hippocampal oxidative stress, BDNF and inflammatory mediators in rats. Physiol. Behav. 184, 6-11. doi: 10.1016/j.physbeh.2017.10.027

Gidlund, E. K., Ydfors, M., Appel, S., Rundqvist, H., Sundberg, C. J., and Norrbom, J. (2015). Rapidly elevated levels of PGC-1alpha-b protein in human skeletal muscle after exercise: exploring regulatory factors in a randomized controlled trial. J. Appl. Physiol. 119, 374-384. doi: 10.1152/ japplphysiol.01000.2014

Halling, J. F., Jessen, H., Nohr-Meldgaard, J., Buch, B. T., Christensen, N. M., Gudiksen, A., et al. (2019). PGC-1alpha regulates mitochondrial properties beyond biogenesis with aging and exercise training. Am. J. Physiol. Endocrinol. Metab. 317, E513-E525. doi: 10.1152/ajpendo.00059.2019 
Hoshino, D., Tamura, Y., Masuda, H., Matsunaga, Y., and Hatta, H. (2015). Effects of decreased lactate accumulation after dichloroacetate administration on exercise training-induced mitochondrial adaptations in mouse skeletal muscle. Physiol. Rep. 3:e12555. doi: 10.14814/phy2.12555

Hu, J., Cai, M., Shang, Q., Li, Z., Feng, Y., Liu, B., et al. (2021). Elevated lactate by high-intensity interval training regulates the hippocampal BDNF expression and the mitochondrial quality control system. Front. Physiol. 12:629914. doi: 10.3389/fphys.2021.629914

Ikeda, S., Kizaki, T., Haga, S., Ohno, H., and Takemasa, T. (2008). Acute exercise induces biphasic increase in respiratory mRNA in skeletal muscle. Biochem. Biophys. Res. Commun. 368, 323-328. doi: 10.1016/j. bbrc.2008.01.095

Ishikawa, R., Fukushima, H., Frankland, P. W., and Kida, S. (2016). Hippocampal neurogenesis enhancers promote forgetting of remote fear memory after hippocampal reactivation by retrieval. eLife 5:e17464. doi: 10.7554/ eLife. 17464

Khalifa, A. R., Abdel-Rahman, E. A., Mahmoud, A. M., Ali, M. H., Noureldin, M., Saber, S. H., et al. (2017). Sex-specific differences in mitochondria biogenesis, morphology, respiratory function, and ROS homeostasis in young mouse heart and brain. Physiol. Rep. 5:e13125. doi: 10.14814/phy2.13125

Kirby, E. D., Muroy, S. E., Sun, W. G., Covarrubias, D., Leong, M. J., Barchas, L. A., et al. (2013). Acute stress enhances adult rat hippocampal neurogenesis and activation of newborn neurons via secreted astrocytic FGF2. eLife 2:e00362. doi: 10.7554/eLife.00362

Kitaoka, Y., Takeda, K., Tamura, Y., and Hatta, H. (2016). Lactate administration increases mRNA expression of PGC-1alpha and UCP3 in mouse skeletal muscle. Appl. Physiol. Nutr. Metab. 41, 695-698. doi: 10.1139/apnm-2016-0016

Kobayashi, R., Maruoka, J., Norimoto, H., Ikegaya, Y., Kume, K., and Ohsawa, M. (2019). Involvement of l-lactate in hippocampal dysfunction of type I diabetes. J. Pharmacol. Sci. 141, 79-82. doi: 10.1016/j.jphs.2019.09.004

Lee, H., Nagata, K., Nakajima, S., Ohno, M., Ohta, S., and Mikami, T. (2018). Intermittent intense exercise protects against cognitive decline in a similar manner to moderate exercise in chronically stressed mice. Behav. Brain Res. 345, 59-64. doi: 10.1016/j.bbr.2018.01.017

Lev-Vachnish, Y., Cadury, S., Rotter-Maskowitz, A., Feldman, N., Roichman, A., Illouz, T., et al. (2019). L-lactate promotes adult hippocampal neurogenesis. Front. Neurosci. 13:403. doi: 10.3389/fnins.2019.00403

Lezi, E., Lu, J., Selfridge, J. E., Burns, J. M., and Swerdlow, R. H. (2013). Lactate administration reproduces specific brain and liver exercise-related changes. J. Neurochem. 127, 91-100. doi: 10.1111/jnc.12394

Little, J. P., Safdar, A., Cermak, N., Tarnopolsky, M. A., and Gibala, M. J. (2010). Acute endurance exercise increases the nuclear abundance of PGC-1alpha in trained human skeletal muscle. Am. J. Physiol. Regul. Integr. Comp. Physiol. 298, R912-R917. doi: 10.1152/ajpregu.00409.2009

Livak, K. J., and Schmittgen, T. D. (2001). Analysis of relative gene expression data using real-time quantitative PCR and the 2(-Delta Delta C(T)) method. Methods 25, 402-408. doi: 10.1006/meth.2001.1262

Lourenco, M. V., Frozza, R. L., de Freitas, G. B., Zhang, H., Kincheski, G. C., Ribeiro, F. C., et al. (2019). Exercise-linked FNDC5/irisin rescues synaptic plasticity and memory defects in Alzheimer's models. Nat. Med. 25, 165-175. doi: 10.1038/s41591-018-0275-4

Luo, Y., Zhu, W., Jia, J., Zhang, C., and Xu, Y. (2009). NMDA receptor dependent PGC-1alpha up-regulation protects the cortical neuron against oxygen-glucose deprivation/reperfusion injury. J. Mol. Neurosci. 39, 262-268. doi: 10.1007/ s12031-009-9196-5

Machler, P., Wyss, M. T., Elsayed, M., Stobart, J., Gutierrez, R., von Faber-Castell, A., et al. (2016). In vivo evidence for a lactate gradient from astrocytes to neurons. Cell Metab. 23, 94-102. doi: 10.1016/j.cmet.2015.10.010

Matsui, T., Omuro, H., Liu, Y. F., Soya, M., Shima, T., McEwen, B. S., et al. (2017). Astrocytic glycogen-derived lactate fuels the brain during exhaustive exercise to maintain endurance capacity. Proc. Natl. Acad. Sci. U. S. A. 114, 6358-6363. doi: 10.1073/pnas.1702739114

Mikami, T., Kim, J., Park, J., Lee, H., Yaicharoen, P., Suidasari, S., et al. (2021). Olive leaf extract prevents obesity, cognitive decline, and depression and improves exercise capacity in mice. Sci. Rep. 11:12495. doi: 10.1038/ s41598-021-90589-6

Newman, L. A., Korol, D. L., and Gold, P. E. (2011). Lactate produced by glycogenolysis in astrocytes regulates memory processing. PLoS One 6:e28427. doi: 10.1371 /journal.pone.0028427
Okamoto, M., Mizuuchi, D., Omura, K., Lee, M., Oharazawa, A., Yook, J. S., et al. (2021). High-intensity intermittent training enhances spatial memory and hippocampal neurogenesis associated with BDNF signaling in rats. Cereb. Cortex 31, 4386-4397. doi: 10.1093/cercor/bhab093

Overgaard, M., Rasmussen, P., Bohm, A. M., Seifert, T., Brassard, P., Zaar, M., et al. (2012). Hypoxia and exercise provoke both lactate release and lactate oxidation by the human brain. FASEB J. 26, 3012-3020. doi: 10.1096/ fj.11-191999

Pellerin, L., Pellegri, G., Bittar, P. G., Charnay, Y., Bouras, C., Martin, J. L., et al. (1998). Evidence supporting the existence of an activity-dependent astrocyte-neuron lactate shuttle. Dev. Neurosci. 20, 291-299. doi: $10.1159 / 000017324$

Pierozan, P., Jerneren, F., Ransome, Y., and Karlsson, O. (2017). The choice of euthanasia method affects metabolic serum biomarkers. Basic Clin. Pharmacol. Toxicol. 121, 113-118. doi: 10.1111/bcpt.12774

Quistorff, B., Secher, N. H., and Van Lieshout, J. J. (2008). Lactate fuels the human brain during exercise. FASEB J. 22, 3443-3449. doi: 10.1096/fj.08-106104

Riske, L., Thomas, R. K., Baker, G. B., and Dursun, S. M. (2017). Lactate in the brain: an update on its relevance to brain energy, neurons, glia and panic disorder. Ther. Adv. Psychopharmacol. 7, 85-89. doi: $10.1177 / 2045125316675579$

Rodriguez-Martinez, E., Martinez, F., Espinosa-Garcia, M. T., Maldonado, P., and Rivas-Arancibia, S. (2013). Mitochondrial dysfunction in the hippocampus of rats caused by chronic oxidative stress. Neuroscience 252, 384-395. doi: 10.1016/j.neuroscience.2013.08.018

Rowe, G. C., Patten, I. S., Zsengeller, Z. K., El-Khoury, R., Okutsu, M., Bampoh, S., et al. (2013). Disconnecting mitochondrial content from respiratory chain capacity in PGC-1-deficient skeletal muscle. Cell Rep. 3, 1449-1456. doi: 10.1016/j.celrep.2013.04.023

Safdar, A., Abadi, A., Akhtar, M., Hettinga, B. P., and Tarnopolsky, M. A. (2009). miRNA in the regulation of skeletal muscle adaptation to acute endurance exercise in C57Bl/6J male mice. PLoS One 4:e5610. doi: 10.1371/ journal.pone.0005610

Safdar, A., Little, J. P., Stokl, A. J., Hettinga, B. P., Akhtar, M., and Tarnopolsky, M. A. (2011). Exercise increases mitochondrial PGC-1alpha content and promotes nuclear-mitochondrial cross-talk to coordinate mitochondrial biogenesis. J. Biol. Chem. 286, 10605-10617. doi: 10.1074/ jbc.M110.211466

Saleem, A., and Hood, D. A. (2013). Acute exercise induces tumour suppressor protein p53 translocation to the mitochondria and promotes a p53-Tfammitochondrial DNA complex in skeletal muscle. J. Physiol. 591, 3625-3636. doi: 10.1113/jphysiol.2013.252791

Saucedo Marquez, C. M., Vanaudenaerde, B., Troosters, T., and Wenderoth, N. (2015). High-intensity interval training evokes larger serum BDNF levels compared with intense continuous exercise. J. Appl. Physiol. 119, 1363-1373. doi: 10.1152/japplphysiol.00126.2015

Short, K. R., Bigelow, M. L., Kahl, J., Singh, R., Coenen-Schimke, J., Raghavakaimal, S., et al. (2005). Decline in skeletal muscle mitochondrial function with aging in humans. Proc. Natl. Acad. Sci. U. S. A. 102, 56185623. doi: 10.1073/pnas.0501559102

Steiner, J. L., Murphy, E. A., McClellan, J. L., Carmichael, M. D., and Davis, J. M. (2011). Exercise training increases mitochondrial biogenesis in the brain. J. Appl. Physiol. 111, 1066-1071. doi: 10.1152/japplphysiol.00343.2011

Sutherland, L. N., Bomhof, M. R., Capozzi, L. C., Basaraba, S. A., and Wright, D. C. (2009). Exercise and adrenaline increase PGC-1\{alpha\} mRNA expression in rat adipose tissue. J. Physiol. 587, 1607-1617. doi: 10.1113/ jphysiol.2008.165464

Suzuki, A., Stern, S. A., Bozdagi, O., Huntley, G. W., Walker, R. H., Magistretti, P. J., et al. (2011). Astrocyte-neuron lactate transport is required for long-term memory formation. Cell 144, 810-823. doi: 10.1016/j.cell.2011.02.018

Tadaishi, M., Miura, S., Kai, Y., Kawasaki, E., Koshinaka, K., Kawanaka, K., et al. (2011). Effect of exercise intensity and AICAR on isoform-specific expressions of murine skeletal muscle PGC-1alpha mRNA: a role of beta(2)adrenergic receptor activation. Am. J. Physiol. Endocrinol. Metab. 300, E341-E349. doi: 10.1152/ajpendo.00400.2010

Takahashi, K., Kitaoka, Y., Yamamoto, K., Matsunaga, Y., and Hatta, H. (2020). Oral lactate administration additively enhances endurance training-induced increase in cytochrome $\mathrm{C}$ oxidase activity in mouse soleus muscle. Nutrients 12:770. doi: 10.3390/nu12030770 
Takimoto, M., and Hamada, T. (2014). Acute exercise increases brain regionspecific expression of MCT1, MCT2, MCT4, GLUT1, and COX IV proteins. J. Appl. Physiol. 116, 1238-1250. doi: 10.1152/japplphysiol.01288.2013

Terada, S., Kawanaka, K., Goto, M., Shimokawa, T., and Tabata, I. (2005). Effects of high-intensity intermittent swimming on PGC-1alpha protein expression in rat skeletal muscle. Acta Physiol. Scand. 184, 59-65. doi: 10.1111/j.1365-201X.2005.01423.x

Tobina, T., Yoshioka, K., Hirata, A., Mori, S., Kiyonaga, A., and Tanaka, H. (2011). Peroxisomal proliferator-activated receptor gamma co-activator-1 alpha gene expression increases above the lactate threshold in human skeletal muscle. J. Sports Med. Phys. Fitness 51, 683-688.

van Hall, G., Stromstad, M., Rasmussen, P., Jans, O., Zaar, M., Gam, C., et al. (2009). Blood lactate is an important energy source for the human brain. J. Cereb. Blood Flow Metab. 29, 1121-1129. doi: 10.1038/jcbfm.2009.35

Wareski, P., Vaarmann, A., Choubey, V., Safiulina, D., Liiv, J., Kuum, M., et al. (2009). PGC-1\{alpha\} and PGC-1\{beta\} regulate mitochondrial density in neurons. J. Biol. Chem. 284, 21379-21385. doi: 10.1074/jbc.M109.018911

Wrann, C. D., White, J. P., Salogiannnis, J., Laznik-Bogoslavski, D., Wu, J., Ma, D., et al. (2013). Exercise induces hippocampal BDNF through a PGC-1alpha/FNDC5 pathway. Cell Metab. 18, 649-659. doi: 10.1016/j. cmet.2013.09.008

Yang, C. H., Huang, C. C., and Hsu, K. S. (2004). Behavioral stress modifies hippocampal synaptic plasticity through corticosterone-induced sustained extracellular signal-regulated kinase/mitogen-activated protein kinase activation. J. Neurosci. 24, 11029-11034. doi: 10.1523/JNEUROSCI.3968-04.2004

Yang, J., Ruchti, E., Petit, J. M., Jourdain, P., Grenningloh, G., Allaman, I., et al. (2014). Lactate promotes plasticity gene expression by potentiating
NMDA signaling in neurons. Proc. Natl. Acad. Sci. U. S. A. 111, 12228-12233. doi: $10.1073 /$ pnas.1322912111

Zawada, I., Masternak, M. M., List, E. O., Stout, M. B., Berryman, D. E., Lewinski, A., et al. (2015). Gene expression of key regulators of mitochondrial biogenesis is sex dependent in mice with growth hormone receptor deletion in liver. Aging 7, 195-204. doi: 10.18632/aging.100733

Zhang, Q., Wu, Y., Zhang, P., Sha, H., Jia, J., Hu, Y., et al. (2012). Exercise induces mitochondrial biogenesis after brain ischemia in rats. Neuroscience 205, 10-17. doi: 10.1016/j.neuroscience.2011.12.053

Conflict of Interest: The authors declare that the research was conducted in the absence of any commercial or financial relationships that could be construed as a potential conflict of interest.

Publisher's Note: All claims expressed in this article are solely those of the authors and do not necessarily represent those of their affiliated organizations, or those of the publisher, the editors and the reviewers. Any product that may be evaluated in this article, or claim that may be made by its manufacturer, is not guaranteed or endorsed by the publisher.

Copyright (C) 2021 Park, Kim and Mikami. This is an open-access article distributed under the terms of the Creative Commons Attribution License (CC BY). The use, distribution or reproduction in other forums is permitted, provided the original author(s) and the copyright owner(s) are credited and that the original publication in this journal is cited, in accordance with accepted academic practice. No use, distribution or reproduction is permitted which does not comply with these terms. 